\title{
CARLOTABOTO
}

\section{Cem anos de discursos sobre a leitura: mais um}

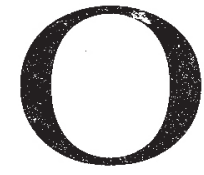

tema da leitura parece ter entrado na moda do debate acadêmico. São inúmeros os trabalhos sobre alfabetização, que tentam trazer novas abordagens, capazes de romper com o senso comum acerca da questão. Discute-se assim as relações entre a alfabetização e a cidadania, explora-se o debate entre os níveis de cultura, as próprias intersecções entre o universo dito erudito e o filtro do popular. Enfim, da lingüística à pedagogia, da literatura à sociologia, a reflexão sobre a leitura entra em pauta. Nesse contexto, em 1989 era publicado na França um livro nascido de uma solicitação da Diretoria do Livro e da Leitura - órgão do Ministério da Cultura francês - ao Centro George Pompidou, através de seu Serviço de Estudo e Pesquisa da Biblioteca Pública de Informação. Tratava-se de uma iniciativa coletiva, congregando cerca de dez investigadores, sob a direção de Anne-Marie Chartier e Jean Hébrard, e que teria por objetivo o estudo das múltiplas modalidades de leitura que perfilaram o território francês no período compreendido entre 1880 e 1980 . A demarcação cronológica é bastante signaficativa, dado que abarca justamente á inflexão havida quanto ao tema da leitura desde operiodo republicano da reforma escolar de Jules Ferry - quando, de uma certa forma, procurava-se aplicar na França alguns dos pressupostos do debate pedagógico da Revolucão Francesa - até a introdução da informática o suas implicaçọes para o âmbito da cultura. Nesse sentido, o objeto da leituraé o sujeito da reflexão nessa obra que originalmente teria sido fruto de um seminário na Escola de Altos Estudos cm Ciências Sociais. A Editora Ática acaba do lançara tradução desse livro, em sua coleção Múltiplas Escritas. No conjunto da leitura, percebe-se um trabalho
CARLOTA BOTO é professora de História da Educação da Faculdade de Ciências e Letras da Unesp - Campus de Araraquara.

Discursos sobre a Leitura 1880-1980, organizado por Anne-Marie Chartier e Jean Hébrard, Sāo Paulo, Ática. 
de equipe, centrado em séries discursivas homogêneas, mediante a abordagem de temas derivados de certas regularidades textuais. Os autores, nessa direção, optaram por centrar o estudo em três unidades básicas: o(s) discurso(s) religioso(s), o(s) discurso(s) dos bibliotecários, o(s) discurso(s) da escola. Discorrendo sobre a longa duração de cem anos, trata-se de "um século de leitura"; na passagem da obrigatoriedade do ler-escrever ao universo do imperialismo da mídia. Os estudos são unânimes em revelar que o século XIX principia envolto por preocupações quanto aos supostos efeitos nefastos impressos nas práticas de leitura. O excesso da leitura era tomado com apreensão: acreditavase que as pessoas estariam lendo demais. $\mathrm{Na}$ outra margem, em meados do século XX, as queixas seriam diametralmente contrárias: dizia-se que as pessoas liam "de menos". É assim que, como destaca a revisora técnica da tradução brasileira, Maria Thereza Fraga Rocco, os autores desses Discursos sobre a Leitura - 1880-1980 "analisam os diferentes posicionamentos teóricos surgidos em relação à leitura na França e delimitam criticamente todo o percurso histórico das manifestações ligadas aos gestos de ler, em diversas instâncias durante todo um século".

Tendo em vista a delimitação mais específica desse amplo conjunto temático, os coordenadores dividiram a obra em três unidades de investigação, sendo cada uma delas precedida por uma parte introdutória, onde são explicitados os textos que vêm a seguir. Assim, primeiramente o leitor se depara com o problema do discurso católico sobre a leitura, um estilo de discurso que tende a pontuar, no próprio prazer da leitura, os vícios que lhe são intrínsecos. Na perspectiva católica, pelo menos nos primeiros anos do período estudado, o livro é percebido como objeto perigoso, por ser naturalmente propenso a desafiar a dogmática da Igreja, a questionar os pressupostos da moral cristã. O livro que produz o abandono, que incita o leitor ao devaneio, ou a perturbadoras ilusões, esse livro não pode ser formador, não pode ser recomendado e deverá ser proscrito de qualquer pedagogia religiosa. A leitura enquanto prática exige, pois, precaução, dado que seu único uso legí- timo é o uso apologético. Por ser assim, a seleção dos livros deveria se colocar como tarefa intransferível do clero, que criteriosamente deverá estruturar obras em consonância com determinados grupos sociais que se apresentam como seus destinatários. Assim, existiriam tantas leituras quanto grupos de leitores que as compartilhassem. De qualquer modo, não se entendia como finalidade da leitura nem o conhecimento nem o entretenimento, mas fundamentalmente a divulgação dos valores católicos. Com a expansão da imprensa e a proliferação de periódicos populares em meados do século XIX - literatura em geral hostil à Igreja e a suas prerrogativas - o clero elege seus três maiores adversários: a escola leiga, pública e estatal, que fugia do controle das congregações religiosas e, por tal razão, era a escola "sem Deus"; o domingo pagão, visto como fonte de decadência moral e de depravação de costumes; e, finalmente, os jornais ímpios, germes da falsidade da informação. Ao estudar o discurso dos bispos, os autores destacam a veemência das publicações da Igreja contra aquilo que parecia ser já um movimento irreversível: a generalização do ato da leitura. Essa ânsia pela leitura, visível em maior escala nas cidades, era apontada como convite à impureza. Até o princípio do século XX, a Igreja não esconde sua desconfiança desse turbilhão de leitores e de livros. Já em meados do século, teria ocorrido uma inflexão do discurso: não se podia mais lutar contra uma realidade que já se tornara sólida e intransponível. A leitura surgia como realidade nas cidades e nos campos e o crescimento do mercado editorial teria se banalizado enquanto fenômeno. Para o clero, lidar com a nova realidade significaria conclamar pais, educadores e confessores a recomendarem leituras adequadas às novas gerações de leitores, sempre prontas a degustar o primeiro livro que surgisse à frente. Tal esforço de moralização e catequização pela leitura inscrevia-se na nova concepção do livro como um instrumento, um veículo material, com o qual se poderia interagir. Ainda nos primeiros anos do século $\mathrm{XX}$, revistas católicas já revelavam seu receio das novidades editoriais: a leitura de romances era bastante temi- 
da, fundamentalmente quando ocorreu o surgimento de edições baratas e acessíveis em grandes tiragens. Os periódicos católicos prescreviam que se deve ler pouco, devagar e muitas vezes as mesmas grandes obras. Ainda no mesmo bloco, há um artigo sobre a imprensa católica dirigida à juventude, desde o período entreguerras até 1980. A renovação incessante do público infantil traria aqui algumas novidades, como é o caso do inusitado consenso surgido nos anos 60: com o ingresso da televisão nas casas de família, não se lia mais. Os discursos alarmistas, que profetizavam o fim da era escrita em prol do império da imagem, deslocaram inclusive o eixo da crítica: a denúncia sobre os efeitos danosos ocasionados pela leitura de jornais cala-se para dar voz à denúncia das tentações da televisão. Ora, se as novas gerações deixaram de ler, seria melhor incentivar qualquer leitura. Com isso, paulatinamente a referência cristã surgirá diluída nos textos, priorizando-se temas capazes de penetrar nos interesses de camadas pouco escolarizadas da população. De qualquer maneira, há um anticomunismo bastante acentuado nos roteiros. Para a Ação Católica, do gesto da leitura deveria depreender-se a militância cristã. Pretendiase assim criar referências compartilhadas que possibilitassem ao leitor o aprendizado das perguntas certas... A obra de Chartier e Hébrard relata esse mosaico de discursos do clero recorrendo a obras de cariz didático, a congressos eclesiásticos, imprensa religiosa e discursos de pastorais. Efetua-se, dessa maneira, um apanhado bastante amplo em termos de fontes documentais, de modo que as diversas abordagens enriquecem-se e complementam-se entre si.

A segunda unidade em que se divide o livro tratará do discurso dos bibliotecários sobre a leitura. A introdução remete já para uma frase de Jules Ferry, que os autores colocam como epígrafe por ser, segundo eles, referência obrigatória em textos, relatórios e documentos oficiais sobre bibliotecas. Dizia o ministro francês da instrução pública que "pode-se fazer tudo pela escola, pelo liceu ou pela universidade; se depois faltar a biblioteca, nada se terá feito" (1). Compreendendo como um movimento uníssono a irradiação do conhecimento produzido e a prosperidade das nações, o credo republicano - dizem os autores - envolveria no mesmo projeto de instrução a escola e a biblioteca. Haveria supostamente um efeito libertador no ato da instrução, fosse pela via da escola, fosse por intermédio exclusivo do livro. Para o mito republicano herdado da Revolução, a escola equalizaria os talentos, trazendo equilíbrio social e diminuindo possíveis distorções ocorridas pela desigualdade de fortunas. Além disso, exerceria um papel social de preparação e capacitação do indivíduo para a cidadania. Ora, caberia à biblioteca a continuidade desse processo de formação do cidadão republicano. Assim como a escola, aliás, a biblioteca, para tanto, deveria ser pública: pública por pertencer ao Estado, pública enquanto estilo de gestão interna, pública como uma concepção de atendimento do usuário. Ao adquirir o controle sobre a instituiçãobiblioteca, o Estado francês paulatinamente adquiriria controle sobre as práticas de leitura; e isso, evidentemente, significava poder. O século XIX presenciaria, então, a constituição progressiva de todo um conjunto de funcionários de Estado, com níveis de formação especializada a carreiras específicas, cuja função precípua seria a formação de leitores. A profissão de bibliotecário adquirirá conotações variadas, de acordo com o período ou até com o estilo da biblioteca: nacional, municipal, universitária, escolar. No capítulo intitulado "Gênese das Concepções Republicanas sobre a Leitura Pública", os autores irão rastrear o percurso da acepção da leitura popular, nos meios letrados franceses naquele período de cem anos. Nos primeiros anos da Restauração, surgiriam as denominadas bibliotecas populares, que representavam um esforço para atingir um contingente mais amplo da população semicultivada. A extensão da alfabetização deveria ser, assim, acompanhada por iniciativas de divulgação de "bons livros", capazes de complementar a tarefa moralizadora da escola primária. Tendo em vista a inculcação de códigos e padrões de conduta, a prescrição de hábitos de civilidade, a biblioteca enceta sua batalha contra a leitura do almanaque, do livro barateado. É a guerra do clássico contra a vulgata, do erudi-
1 Jules Ferry, apud AnneMarie Chartier e Jean Hébrard, Discursos sobre a Leitura, p. 111 
to contra o popular, e, em tal esquadro, a biblioteca destacar-se-ia enquanto "agência supervisionada", capaz de derrocar a leitura refém das leis de mercado. Sobre isso, os autores comentam:

"Procurando criar obstáculos às vendas em feiras e ao aluguel, as bibliotecas fazem do impresso um objeto de produção e difusão controladas, tornando sua leitura territorializada e limitada. Contrariamente ao livro comprado ou tomado de empréstimo nas redes habituais do universo privado ou mercantil, o livrolido na biblioteca ou pela biblioteca se impõe ao leitor num espaço e num tempo que pouco the pertencem. Toda apropriação concreta do livro, real ou simbólica (conservação para releitura, rabiscos, anotações, etc.), é proibida a quem o toma emprestado e pode mesmo ser objeto de uma sanção. Toda reciprocidade na troca - própria da sociabilidade da leitura (Chartier, 1987), tanto erudita quanto comum - se choca com o anonimato do empréstimo e com a rotatividade das obras. O objetivo central da instalação das primeiras bibliotecas é transformar o leitor em um leitor acompanhado, mesmo quando ele já está fora do circuito da escolarização" (2).

A biblioteca pública aparece, antes de tudo, como reserva de patrimônio. Já na Revolução Francesa, com o confisco dos bens dos emigrados, do clero e dos suspeitos, muitos acervos importantes transformam-se em bens nacionais. Os ideólogos da Revolução não se esqueceriam de defender a leitura pública em bibliotecas nacionais como estratégia de consolidação daqueles novos tempos que se parecia querer inaugurar. Embora o pressuposto da biblioteca seja o acesso do leitor aos livros pertencentes ao patrimônio público, o estilo dos bibliotecários do início do século XIX tendia a priorizar a preservação em detrimento da divulgação do livto. Sendo assim, os estudos atestam que o leitor que manuseava com demasiada familiaridade o suporte material impresso era visto com desconfiança, como se prejudicasse o bom andamento da biblioteca. Enquanto disposi- tivo de sociabilidade, a biblioteca pública agiria no sentido de criação de certos hábitos e modalidades de leitura compartilhada, na transmutação da solidão da leitura silenciosa em intercâmbio e convívio entre as pessoas. Por outro lado, pretendendo divulgar o que à época se entendia por "conhecimentos úteis", a biblioteca exercia sua tarefa pedagógica. A laicização do livro era, portanto, atitude que viria acompanhada da busca de moralização do povo. As bibliotecas escolarés são, nesse esforço, emblemáticas. Em um certo sentido, elas serviam também aos professores primários, que eram, a despeito de sua devoção profissional, sujeitos pouco instruídos, necessitados do contato com o bom livro. E o bibliotecário, por sua vez, era o "instituidor" do povo.

O livro contempla um capítulo sobre a Associação dos Bibliotecários Franceses, intitulando-se "O Nascimento de uma Profissão". Tal associação foi criada em 1906, tendo uma revista posta em circulação a partir de 1907. Os objetivos a que se propunham eram o de promover a profissão, mediante reivindicações de salário, status e formação, além da defesa de uma dada concepção de bibliotecário. Este não é um leitor; ou se o for, será um tipo muito particular de leitor, posto que não lê para si e sim para os outros. Profissional da cultura alheia, ele "põe à disposição dos outros as riquezas intelectuais que guarda" (3). A competência desse profissional conjugaria conhecimento da técnica, do livro e do leitor. Os autores constatam que, no discurso dos bibliotecários, alguma mudança ocorreu no transcurso da guerra de 1914, trinta anos depois de se haver instituído a instrução obrigatória. Anota-se que teriam sido os alunos da geração Jules Ferry quem, pela primeira vez, delineou a distração como um dos objetivos da leitura. A biblioteca, a partir de então, adqui riria conotação comercial, como se fosse uma loja que, de vez em quando, quer renovar seu estoque. Com espaço limitado, os acervos da biblioteca só podem crescer se alguma coisa for dali retirada. Cada vez mais, pensa-se a biblioteca como o'território de uma leitura útil. que habilite oindivíduo, proporcionando a ele ora conhecimento, ora distração.

Na sequência, a obra aborda o tema da tentativa de aculturação social emprecndida 
nesse movimento, que paulatinamente caminhava das cidades para o campo, passando inclusive por bibliotecas ambulantes que rodavam a partir de 1945 pelas estradas francesas. Era, no parecer dos autores, a "batalha da leitura republicana", que precisava vencer, no campo, "o obscurantismo, a religião e o voto conservador" (4). Depois vem a época de medo do rádio e do cinema, em um verouvir que era identificado como infeliz substituto do ler-escrever árido e convencional. A tônica do discurso centrar-se-á, cada vez mais, sobre a queixa pela ausência de leitura e pelos deploráveis (supostos) efeitos de passividade desencadeados pelo cinema quando posto em confronto com a literatura. Mais uma vez, passa-se, nos referidos cem anos, das observações quanto aos perigos do excesso de leitura às lamentações de sucessivas gerações sobre a juventude que não lê mais...

Se o livro da biblioteca situa-se - dizem os autores - na zona fronteiriça entre o trabalho e o lazer, a leitura da escola ficaria reduzida a um tipo muito particular de trabalho: o trabalho escolar. Reservando, para o desenvolvimento do tema, praticamente metade da obra, os autores dividem a terceira unidade em três seções que, no conjunto, abarcam o que se qualificou de discursos da escola: "a lição dos textos oficiais"; "entre o ministro e o professor primário, os discursos pedagógicos intermediários"; "crise da escola, crise da leitura”. Nos termos da introdução:

"Falta a escola. Por muito tempo o lugar natural para a formação literária das elites e também para a alfabetização popular, a ela já foram creditados (e talvez ainda o sejam, de modo confuso) poderes políticos e institucionais para emitir um discurso autorizado sobre os fins e os meios da leitura. Hoje, quando o lazer, a cultura e a própria formação ingressam na era industrial, a escola parece assediada por todos os lados, nas suas certezas e seus costumes. Contrariamente às Igrejas, cujos discursos explícitos foram sendo reduzidos ao silêncio (embora seus dispositivos editoriais, como vimos, guardem uma atualidade bastante eficaz), contrariamente aos profissionais da leitura pública, que atua- lizam sem cessar, pelo futuro da tecnologia, seus sonhos de um mundo no qual ninguém escaparia às necessidades e aos usos da leitura, a escola parece condenada a dizer a um só tempo o que ela foi e o que é, em ambições perdidas e sucessivas derrotas. Situada entre um passado glorioso, longínquo o bastante para que se confunda com uma vocação natural, e um presente em que se concentram todos os perigos e todas as desilusões, ela atrai para si olhares e expectativas, mas também sarcasmos e condenações" (5).

Apesar de historicamente se haver delegado à escola o ensino da leitura, parece bastante complexa a relação da escola com o aprendizado do ler. Para demarcar sua competência, existiriam inúmeros discursos escolares a propósito da leitura, cujas especificidades precisariam ser estudadas. Por outro lado, nem tudo o que a escola prescreve faz parte de seu cotidiano, e muitos dos próprios objetivos enunciados não podem ser identificados como finalidades reais da instituição. De fato, uma leitura atenta da escolarização enquanto processo revelaria que o sistema escolar se apropria, de maneira muito particular, do acervo de conhecimentos historicamente acumulados, chegando a parecer que os conteúdos pedagógicos foram mesmo inventados ali, dentro da própria escola. O estudo sobre a leitura da escola abarca, por essa razão, no recorte efetuado pelos autores, "dois espaços discursivos" (6): por um lado os textos oficiais, e, por outro, aqueles destinados a formar e a informar os professores. Os autores falam mesmo em um diálogo entre as recomendações de ministros, inspetores, órgãos centrais da administração escolar e a vida que se projetava para a escola, quando se pensava em falar para os profissionais da escolarização. Seriam representações entrecruzadas, que possibilitariam a reconstituição das formas que a escola vinha assumindo no período em pauta e o que ela dizia sobre o tema da leitura.

Em um primeiro momento abordam-se os textos utilizados nos colégios e escolas franceses para o ensino da leitura e a formação dos hábitos do leitor. A origem da leitura
4 Idem, ibidem, p. 176.

5 Idem, ibidem, p. 247. 6 Idem, ibidem, p. 249 
escolar estaria, segundo os estudiosos do tema, nas tentativas alfabetizadoras das petites écoles do Antigo Regime. Em termos do ambiente europeu, a rigor, o esforço da alfabetização confundir-se-ia com o da catequese. A própria acepção da técnica da leitura confunde tal competência com a memorização de um texto, que é, a princípio, o texto sagrado. Por tal razão, os primeiros compêndios escolares tinham a forma de catecismos, organizados no esquema de perguntas e respostas. Acerca do tema, os autores remarcam: "ler se confunde então com memorizar. Os métodos pedagógicos em uso contribuem aliás para essa confusão: cada aluno deve ler e reler um texto em voz alta até que, quando solicitado, mostre-se capaz de reproduzi-lo imediatamente" (7). Por muito tempo - sabese - a escola funcionou assim. Mas para os autores do livro, a "era da leitura escolar" principiaria no último terço do século XIX. A partir dali, o Estado definitivamente se apropriaria da função que durante muito tempo estivera reservada à Igreja, e o ensino da leitura passaria a fazer parte de uma empreitada coletiva de moralização, mediante a qual se deveria proceder a toda uma redefinição em termos de valores adotados e de conhecimentos selecionados. O Estado francês pretendia obter consenso simbólico, que permitisse seu próprio fortalecimento. É preciso ler, e ler bem. Haveria, segundo autores da época, um cariz de civismo impresso na leitura em voz alta. Com a formação do costume de leitura escolar de trechos seletos, o estudante teria acesso a belas páginas da literatura nacional, tomaria contato com verdadeiros exemplos do francês escrito e, aprendendo a ler, mostrar-se-ia capaz de expressar suas idéias de maneira mais precisa e clara. Sabe-se - embora a obra em questão não aborde mais detidamente o assunto - que a leitura escolar inscrevia-se no próprio esforço de formação de uma identidade nacional francesa, porque eram inúmeras as regiões da França que não se expressavam fora de seu patois regional. Ainda a propósito dessa leitura da escola, a obra discorre sobre as prescrições acerca do ensino da leitura nas diferentes grades curriculares, que são organizadas nesse período longo. Assim - pergunta-se para procurar responder - quando é que o Estado francês teria priorizado o ditado ou as cópias, a explicação ou a recitação, a leitura corrente ou a dirigida, a leitura em voz alta ou a silenciosa? Seja qual for a modalidade do exercício de leitura, o que se pretende é dirigir o olhar do aluno. Sobre isso, comentam os autores:

"Para que a explicação francesa seja um exercício de formação, deve satisfazer a pelo menos duas exigências: transformar a criança pelo contato com uma pessoa percebida a um só tempo como estranha e como modelo; conservar o caráter de sacralidade do tex to que transforma a criança, o que, de certa forma, põe o trabalho fora do seu alcance. A primeira condição é preenchida pela própria exigência do exercício: o aluno deve experimentar, na sua inteligência como na sua sensibilidade, a força das idéias e da afetividade do autor. A segunda está implícita na finalidade atribuída à explicação: provocar a admiração" (8).

Nos anos 70, pela primeira vez, a atividade de leitura em voz alta receberia críticas por parte dos especialistas da educação. O aprendizado da leitura passa a ser encarado como a aquisição de um conjunto de estruturas de compreensão cultural, tidas por mais importantes do que o tradicional e ultrapassado ritual da leitura escolar. O objetivo do estudo dos textos centrar-se-á na comunicação e expressão e o próprio lugar da explicação irá progressivamente sendo ocupado por exercícios de resumo e de análise. Seja como for, de lá para cá - constatam os autores - os alunos não deixaram de ler na escola. Mudou-se apenas a forma de se proceder essa leitura, já que saber ler, na atualidade, significaria possuir certas destrezas, repertório e competências que habilitem o indivíduo para o reconhecimento de mensagens também expressas por imagens, por instrumentos tecnológicos ou por recursos da audiocomunicação.

Em seguida há todo um capítulo contendo "observações sobre a leitura" expressas por políticos e notáveis daquela "república iniciante" do final do século passado. Tratava-se, na verdade, de palestras, conferências, 
congressos ou cursos que vieram depois a ser publicados, constando do arquivo da Biblioteca da Escola Normal de Chartres. Nem sempre o discurso proclamado coincide com as reais intenções de seus autores; neste caso, certamente, havia muito de retórica... Nos termos do texto: "o que esses discursos dizem sobre a leitura? A maior parte trata de seus objetivos, os quais, para esses homens de tribuna, são evidentemente políticos. Ler é instruir e a instrução ilumina. Este é o preço da República" (9). Ao libertar do obscurantismo e das superstições, a escola teria uma função liberadora, no parecer daqueles republicanos do século XIX. O conhecimento, na mais perfeita herança iluminista, era tomado como fonte de emancipação social e a própria democracia se construiria mediante o voto esclarecido e consciente. Era essa a matriz da mitologia política sobre o lugar social ocupado pela escola, pela instrução, pelo aprendizado da leitura. No entanto, como revela o capítulo intitulado "O Professor Primário e a Leitura no Departamento de Pas-de-Calais", haveria, para o ato de ler, não apenas a sacralização, mas a própria teatralização do objeto. Com a prescrição de boas leituras, a escola encaminharia comportamentos sociais recomendáveis, transmitindo, pelos textos indicados, controles e significados. Por tal razão, eram muito comuns os discursos que incentivavam a partilha da leitura escolar com os familiares durante as horas de serão doméstico. É como se houvesse, em tais ocasiões, um catártico efeito de "fusão emocional em torno do livro" (10). Ler um texto e compartilhá-lo era imprimir-lhe nova vida e trazer também novas experiências para a vida em sociedade. A leitura oralizada em voz alta representava também a conquista progressiva da correção da pronúncia. Se havia, por um lado, esse "fervor lírico empregado para enaltecer o livro" (11) e o gosto pela leitura que a escola desenvolve, por outro lado, havia certa reticência em relação à possibilidade de a leitura surgir como substituta da autoridade impressa na palavra do professor. A aula, enquanto tal, era compreendida enquanto oralização de conteúdos culturais por parte de um mestre que aprendeu, durante seu período de formação, que não se deve utilizar livro algum durante a exposição.

Uma investigação sobre a escolarização das práticas de leitura não poderia ser concluída a contento sem deter-se no estudo dos manuais escolares: a seiva da escola primária. Dizem os autores no capítulo dedicado aos manuais de leitura:

"Os manuais de leitura são a verdadeira estrada para se entrar no mundo escrito, como deixa claro a leitura dos prefácios que se sucedem ao longo do século. Autores e editores não deixam um só momento de recordar que tarefa exaltante e difícil se esconde na modéstia do manual. Dentre todos os livros, o de leitura escolar é aquele sobre o qual uma pessoa terá passado a maior parte de sua vida - um ano, talvez dois; ou mais ainda, nas classes de diferentes níveis -, no ritmo teórico de uma leitura por dia, preparada ou revista em casa" (12).

A pesquisa efetuada sobre os manuais procurou reconhecer as principais características daquele material impresso, desde a durabilidade da edição, as ilustrações, capas, até as fórmulas de divulgação que presidem algumas das iniciativas editoriais. Além disso, os autores atentam para o estudo dos prefácios, que, na maioria das vezes, traziam indicações e recomendações, estabelecendo, com isso, um certo código entre os leitores que chegam até ele. Tal tentativa de imposição de uma ortodoxia da leitura não elimina, em hipótese alguma, a invenção criativa que a leitura produz sobre aquele que, ao ler, transforma o que leu. A idéia de apropriação bastante cara aos partidários daquilo que Roger Chartier qualifica de história cultural do social -, de um certo modo, está pressuposta por todo esse grupo que escreveu em conjunto essa obra. Sobre os manuais utilizados em sala de aula, caminha-se do modelo das edições duráveis - cuja configuração gráfica permite a resistência pelo decorrer de vários anos - para o universo das edições luxuosas, reservadas muitas vezes para coleções, festas e prêmios escolares; até que se chegaria, no final do período estudado, nas edições descartáveis, quando cada livro dura
9 Idem, ibidem, p. 348. 10 Idem, ibidem, p. 382 11 Idem, ibidem, p. 384 12 Idem, ibidem, p. 390 
apenas o tempo de sua primeira leitura. Seja como for, o manual escolar, que a princípio aparece no modelo enciclopédico do livro único para depois ramificar-se em consonância com a "emancipação das disciplinas escolares" (13), situa-se como um tipo muito particular de leitura: a primeira; aquela que recorda a singularidade das estréias. De qualquer maneira, para além do óbvio intento de moralização, o livro de leitura toma, cada vez mais, a forma da narrativa para estruturar-se perante um tipo específico de exercício escolar: a lição da leitura na aula.

Além disso, a obra aborda o tema em questão em uma revista destinada a profissionais da pedagogia: L'Education Nationale. Esse semanário, publicado entre 1946 e 1984, teria por finalidade a irradiação e o aprofundamento do debate pedagógico na sociedade francesa, estimulando a partilha e o confronto de idéias e experiências. O estudo daquele periódico permitiu à equipe de investigadores constatar quais eram os eixos do debate pedagógico entre os educadores franceses nas diferentes épocas e como a reflexão sobre a leitura era ou não tributária desse debate mais geral, que ora se centrava na questão da democratização do ensino, ora tendia a indagar sobre os fatores envolvidos no rebaixamento dos padrões escolares, ou ainda optava por temas como o fracasso escolar, as técnicas audiovisuais, a matemática moderna, etc. Após trabalhar os objetos mais recentes, nomeados no capítulo "Novos Suportes, Novos Lugares de Leitura: da Biblioteca à Mediateca", e, a seguir, travar a discussão sobre a explosão de referências outras, exteriores e posteriores à leitura, enquanto frutos da modernidade, os autores refletem sobre a dimensão cultural e simbólica submersa na desleal concorrência dos meios de comunicação de massa sobre os conhecimentos que a escola se incumbia de transmitir. Sob esse aspecto, constata-se a resistência à mudança e a própria dificuldade de incorporação, por parte da escola, dos novos instrumentos e materiais, originados como fruto do progresso da ciência e da tecnologia. Pelas palavras dos autores:

"A escola, como seria previsível, não consegue instaurar uma pedagogia eficaz da palavra viva [...] ; ela não consegue integrar, salvo de modo marginal e temporário, os meios audiovisuais, grandes consumidores de tempo [...]. Na escola, a revolução McLuhan nem entrou. A leitura, que sofrera concorrências e reexames, triunfa novamente, mas ao preço de uma metamorfose. Um 'saber ler' que não é mais 'o gosto pela leitura', nem mesmo 'o desejo de ler', pode ser encontrado na base desse dispositivo, por se tratar de uma competência que é a condição sine qua non de todos os êxitos escolares. Os valores hedonísticos da sociedade de consumo, que interferem de modo constante nos procedimentos escolares, não chegam portanto a se tornar os valores da escola. Esta continua sendo definida como um espaço onde se trabalha, onde se ensina e onde, portanto, se pode fracassar; jamais um espaço de convivência e de sociabilidade".

Para finalizar, como qualquer original flui melhor do que a melhor das traduções, o texto é, por definição, mais rico do que sua resenha. Ao pretender falar sobre o que os outros escreveram, efetuamos nós mesmos um gesto de apropriação, uma reinvenção, um discurso a propósito dos Discursos sobre a Leitura. Mesmo assim, creio não ser difícil convencer o leitor atencioso da relevância do debate sobre o problema da leitura em uma sociedade já rendida aos encantos da computação. Subsistirá, num futuro próximo, o ato de ler fora da tela do computador? O livro persistirá em sua materialidade, ou a civilização inventará outro objeto com uma nova forma? Como ler, por exemplo, Ilusões Perdidas de Balzac por computador? Proporcionando e incitando inúmeras indagações, a obra de que aqui tratamos cumpre satisfatoriamente seu papel pedagógico. O mercado editorial brasileiro sai enriquecido com a tradução desse livro, nitidamente construído pela mão de vários autores e que parece ser mesmo filho de seu tempo. Um trabalho como esse surge hoje como referência necessária para estudantes e pesquisadores de história social, de educação, de literatura, de lingüística, revelando que o ambiente da história ainda pode ser dinamizado pela confluência... 